\title{
Correction to: High efficiency inactivation of microalgae in ballast water by a new proposed dual-wave UV-photocatalysis system (UVA/UVC-TiO $\left.{ }_{2}\right)$
}

\author{
Zheng Lu ${ }^{1} \cdot$ Kun Zhang ${ }^{1} \cdot$ Xiaolei Liu $^{2} \cdot$ Yue Shi ${ }^{1}$ \\ Published online: 5 February 2020 \\ (C) Springer-Verlag GmbH Germany, part of Springer Nature 2020
}

Correction to: Environmental Science and Pollution Research (2019) 26:7785-7792 https://doi.org/10.1007/s11356-019-04268-1

In the third paragraph of Introduction, the sentence "Few scholars have conducted static studies on dual-wavelength UV photocatalytic technologies (Ma 2018)" should be added after the sentence "Zhao et al. Employed UVA photocatalytic $\mathrm{TiO} 2$ method to treat Bacillus cereus spores with protective outer wall in air (Zhao et al. 2009)". And the reference of "Ma LS (2018) Study on the Inhibitory Effect of Different Wavelengths of UV-Photocatalysis on Dicrateria Under Light and Dark. Dissertation, Dalian Maritime University" should be included as well.

Publisher's note Springer Nature remains neutral with regard to jurisdictional claims in published maps and institutional affiliations.

The online version of the original article can be found at https://oi.org/ 10.1007/s11356-019-04268-1

Yue Shi

shiyue2046@163.com

1 College of Power and Energy Engineering, Harbin Engineering University, Harbin 150000, China

2 School of Economics and Management, Harbin Engineering University, Harbin 150000, China 